\title{
Subsoil compaction of a clay soil in South-East Norway and its amelioration after 5 years**
}

\author{
Till Seehusen ${ }^{1}{ }^{*}$, Anneka Mordhorst ${ }^{2}$, Roland Riggert ${ }^{2}$, Heiner Fleige ${ }^{2}$, Rainer Horn ${ }^{2}$, and Hugh Riley ${ }^{1}$ \\ ${ }^{1}$ Department of Grain and Forage Seed Agronomy, NIBIO Apelsvoll, Nylinna 226, 2849 Kapp, Norway \\ ${ }^{2}$ Institute for Plant Nutrition and Soil Sciences, Christian-Albrechts-Universitaet Kiel, Hermann-Rodewald-Straße 2, 24118 Kiel, Germany
}

Received February 10, 2021; accepted April 6, 2021

\begin{abstract}
The main objective was to evaluate to what extent subsoil compaction on an arable clay soil (Stagnosol (Drainic)) may be alleviated after 5 years under the climate conditions in South-East Norway. Therefore, field plots which had been ploughed and under minimum tillage were compacted through wheel impact $(10 \mathrm{x})$ with a $6.6 \mathrm{Mg}$ wheel load. Samples were taken from the 'compacted' and 'non-compacted reference' treatments at depths of 40 and $60 \mathrm{~cm}$ both before and directly after compaction and again 5 years later. The soil physical parameters revealed that pre-compression stress, bulk density, air capacity, air conductivity and saturated hydraulic conductivity at depths of 40 and $60 \mathrm{~cm}$ were impaired by compaction, especially under ploughed. After 5 years, bulk density and pre-compression stress remained almost unchanged, while air capacity, air conductivity and saturated hydraulic conductivity had increased at both the 40 and $60 \mathrm{~cm}$ depth on both plots as compared to the compacted state and to $\mathrm{R}$ for the most part, indicating the recovery of the soil structure in the subsoil. The compaction status evaluated by the 'compaction verification tool' indicates the relative reduction of 'harmful soil compaction' (after wheel impact) with a change towards 'slightly harmful compaction' for the most part with an as yet limited saturated hydraulic conductivity at both depths after 5 years.
\end{abstract}

Keywords: soil compaction, multiple wheel impact, clay soil, structural regeneration, minimum tillage, conventional tillage

\section{INTRODUCTION}

Soil compaction due to traffic on agricultural land is one of the main causes of the physical degradation of soil and yield stagnation in Scandinavia and other European

*Corresponding author e-mail: tillseehusen@nibio.no

**This work was part of AGROPRO, financed by Bionærprogrammet, Norwegian Research Council (No. 225330, 2013-2017). countries. Soil compaction is also of growing concern in Norway, mainly due to increasing production costs and economic pressure which leads to the use of heavier machinery and also to more contract machinery operation on smaller farms. Climate change in Norway exacerbates this dilemma due to higher rainfall during the spring season and harvest period (Hanssen-Bauer et al., 2015). This leads to a reduced number of days workable for field operations and thus to an increasing compaction risk when machinery is used under unfavourable soil conditions. Soil compaction leads to restricted root growth as well as reduced aeration and infiltration (Arvidsson and Håkansson, 2014). The latter may cause stagnic (temporarily anaerobic) conditions and thereby reduce the length of the growing season and also increase the risk of surface water runoff and erosion (Hartmann et al., 2012; Keller et al., 2019; Rogger et al., 2017). Apart from the avoidance of soil compaction, it is crucial to find suitable strategies to loosen soil compaction caused by wheel impact under non-workable conditions, which are in some cases almost inevitable under practical conditions. Special attention should be paid to compaction below the ploughed layer $(>25 \mathrm{~cm})$ arising from the use of heavy machinery when the soil is most susceptible to deformation, e.g., when the soil is at field capacity or wetter (Batey, 2009). While damage resulting from compaction in the ploughed layer may be alleviated after four to five years (Håkansson et al., 1987), through biological,

(C) 2021 Institute of Agrophysics, Polish Academy of Sciences 
climatic (swelling/shrinkage or freeze/thaw cycles) and anthropogenic influences such as tillage (Gysi et al., 1999), these effects are limited or absent in the subsoil and the techniques required to remedy compacted subsoil are rare (Lebert et al., 2007). In contrast, further plastic soil deformation due to additional wheel impact over the years cannot be ruled out (Horn and Lal, 2020).

Approximately $70 \%$ of Norwegian cereal production takes place along the Oslo fjord (Seehusen and Uhlen, 2019), where soils are characterized by high clay and silt contents. These soils may be exposed to both, freezing and thawing cycles in winter as well as shrinking and swelling in summer. Both are natural processes which may help to alleviate soil compaction (Dexter, 1988; Jabro et al., 2014). Nevertheless, it is often assumed that subsoil compaction will persist over a long period even under northern climatic conditions (Håkansson and Reeder, 1994; Lamandé et al., 2012; Lipiec, 2012; Riggert et al., 2017; Saini, 1978; Wolkowski, 1990).

The natural regeneration of subsoil compaction has not yet been investigated with clay soil under the climatic conditions of South-East Norway. The main objective of this paper is to determine to what extent the soil recovered from subsoil compaction after 5 years in south eastern Norway, where the climate is characterized by long, cold winters and relatively short growing seasons. The state of subsoil compaction is characterized by precompression stress $(\mathrm{Pc})$, bulk density (BD), air capacity (AC), air conductivity $\left(\mathrm{K}_{\mathrm{a}}\right)$ and the saturated hydraulic conductivity $\left(\mathrm{K}_{\mathrm{s}}\right)$ of soil samples from both non-compacted and compacted plots (directly after multiple wheel impacts with heavy machinery of $36 \mathrm{Mg}$ total weight) and five years after the compaction event. Plots of previous ploughing and minimum tillage treatments are compared. Furthermore, the compaction verification tool of Zink et al. (2011) has been used to illustrate the extent of potentially harmful subsoil compaction and the potential recovery of the compacted plots.

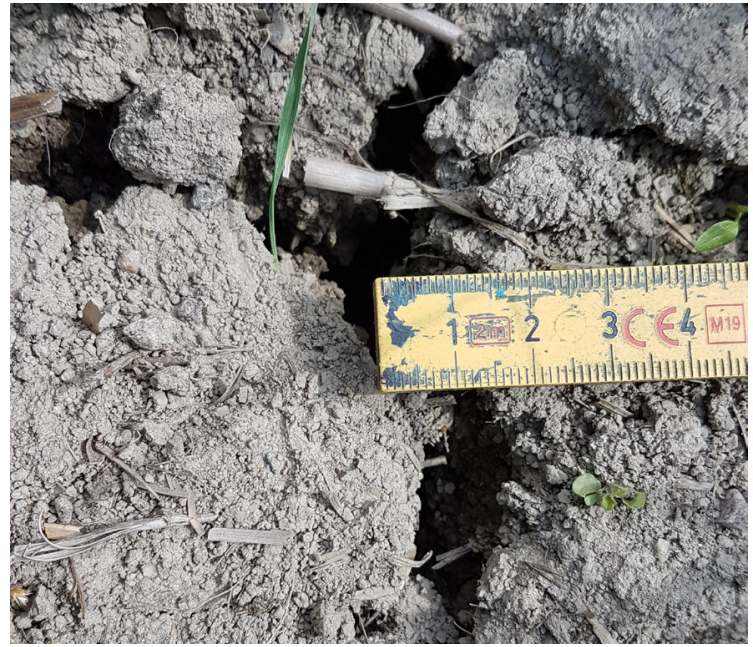

Fig. 1. Cracks in clay soil due to drying at the study site.

\section{MATERIAL AND METHODS}

Field measurements and sampling took place at Øsaker, Sarpsborg $\left(59^{\circ} 23^{\prime} \mathrm{N}\right.$ and $11^{\circ} 02^{\circ} \mathrm{E}, 40 \mathrm{~m}$ above sea level) in southeastern Norway. The soil is a Stagnosol (Drainic) (US Working group 2014, FAO, 2015) derived from postglacial marine deposits, it is characterized as a clay loam with $33 \%$ clay and $44 \%$ silt in the topsoil, overlying a heavy clay ( $46 \%$ clay) subsoil with stagnic properties. The site is artificially drained to about $80 \mathrm{~cm}$ depth with $8 \mathrm{~m}$ spacing and characterized by a high shrinkage potential which give rise to vertical cracks (Fig. 1). The topsoil horizon has 'medium' to 'high' organic matter and soil acidity levels (Ad-hocAG Boden 2005) (Table 1). Details about the field site and a field map are presented in Seehusen et al. (2014a and b).

All treatments were performed on the same location as a former soil tillage trial that was established in 2000 with oats (Avena sativa L.) and (winter) wheat (Triticum aestivum L.) grown each year in rotation. This previous trial included two tillage treatments, autumn ploughing $(\mathrm{P})$ for

Table 1. Soil properties of the two reference profiles under $\mathrm{P}$ - ploughing, $\mathrm{M}$ - minimum tillage, OM - organic matter content, Texture class (TC) and horizons according to FAO (2006)

\begin{tabular}{|c|c|c|c|c|c|c|c|c|}
\hline \multirow{2}{*}{ Tillage } & \multirow{2}{*}{ Horizon } & \multirow{2}{*}{$\begin{array}{l}\text { Depth } \\
(\mathrm{cm})\end{array}$} & \multirow{2}{*}{$\mathrm{pH}\left(\mathrm{CaCl}_{2}\right)$} & $\mathrm{OM}$ & Sand & Silt & Clay & \multirow{2}{*}{$\mathrm{TC}$} \\
\hline & & & & \multicolumn{4}{|c|}{$(\%)$} & \\
\hline \multirow{3}{*}{$\mathrm{P}$} & Ap & $0-40$ & 4.6 & 4.8 & 23 & 43 & 34 & $\mathrm{CL}$ \\
\hline & $\mathrm{Cg}$ & $40-80$ & 4.8 & 1.7 & 23 & 45 & 32 & $\mathrm{CL}$ \\
\hline & $2 \mathrm{Cg}$ & $80-150$ & 6.1 & 1.2 & 10 & 44 & 46 & $\mathrm{SiC}$ \\
\hline \multirow{3}{*}{ M } & Ap* & $0-30$ & 4.8 & 3.8 & 24 & 44 & 32 & $\mathrm{CL}$ \\
\hline & $\mathrm{Cg}$ & $30-50$ & 5.2 & 1.2 & 20 & 46 & 34 & $\mathrm{CL}$ \\
\hline & $2 \mathrm{Cg}$ & $50-120$ & 6.1 & 0.7 & 10 & 44 & 46 & $\mathrm{SiC}$ \\
\hline
\end{tabular}

*Previously ploughed. CL - Clay loam, SiC - Silty clay. 
both crops and minimum tillage (M) (direct drilling for wheat/shallow harrowing for oats). These treatments were performed up until the spring of 2010, thus providing the basis for investigating the long-term tillage effects of contrasting tillage regimes on soil structure (Seehusen et al., 2014a). No tillage was performed in autumn 2010 or in spring 2011 prior to the compaction experiment.

The compaction experiment took place in early summer 2011 on plots from the previous P and M treatment. Multiple (10x) passes with a tractor slurry tank combination with a wheel load (trailer) of $6.6 \mathrm{Mg}$ and a total weight of $36 \mathrm{Mg}$ were performed under workable soil moisture conditions, at around $85 \%$ of the assumed field capacity for Norwegian clay soils $(-10 \mathrm{kPa})$ in the topsoil and under slightly moister conditions in the deeper soil layers (88\%). Details may be found in (Seehusen et al., 2014a and b). After compaction in 2011, both plots were ploughed (wheels in the furrow,
$25 \mathrm{~cm}$ ) each autumn and barley (Hordeum vulgare L.) was sown each spring. The terms $P$ and $M$ treatment used in this study therefore refer to the treatments before 2011.

During the five-year period, the field was managed (e.g. seeding, harvesting) in a similar manner to the surrounding fields. Additional compaction was avoided as much as possible by only allowing wheel impact to occur under workable conditions, reducing the incidence of wheel impact and avoiding the use of heavy machinery.

Weather data (Table 2) for the research period were collected from the local weather station (Øsaker, 59 $23^{\prime}$ $\mathrm{N}$ and $11^{\circ} 02^{\prime} \mathrm{E}, 40 \mathrm{~m}$ above sea level). This station only registered soil temperature at a $20 \mathrm{~cm}$ depth. Soil temperatures, including data from the subsoil (from 2013 onwards) (Table 3) were therefore obtained from the nearest weather stations located approximately 20 and $60 \mathrm{~km}$ from the research field.

Table 2. Deviations in mean air temperature $(2 \mathrm{~m}$ height $)$ and precipitation for the weather station at Øsaker during the research period (www.lmt.nibio.no) relative to the long-term average of temperature and precipitation (1961-1990) (Aune, 1993; Førland, 1993). Precipitation for the winter months obtained from Rygge climate station

\begin{tabular}{|c|c|c|c|c|c|c|c|}
\hline Month & Normal & 2011 & 2012 & 2013 & 2014 & 2015 & 2016 \\
\hline \multicolumn{8}{|c|}{ Temperature $\left({ }^{\circ} \mathrm{C}\right)$} \\
\hline January & -3.8 & / & +1.9 & -1.0 & +1.6 & +4.5 & -2.5 \\
\hline February & -3.7 & / & +1.1 & +0.1 & +5.5 & +4.0 & +2.8 \\
\hline March & -0.2 & 1 & +4.6 & -2.8 & +4.0 & +3.1 & +2.5 \\
\hline April & 4.6 & / & -0.4 & -1.0 & +2.3 & +1.9 & +1.1 \\
\hline May & 10.4 & / & +1.0 & +1.6 & +0.8 & -1.7 & +1.4 \\
\hline June & 14.6 & / & -2.2 & -0.4 & +0.4 & -1.3 & +1.3 \\
\hline July & 16.7 & +0.4 & -1.9 & +0.5 & +3.3 & -1.4 & / \\
\hline August & 15.6 & -0.3 & -1.2 & +0.1 & -0.1 & +0.4 & / \\
\hline September & 11.4 & +1.3 & -0.6 & +0.0 & +1.1 & +0.8 & / \\
\hline October & 7.0 & +1.3 & -2.6 & +0.6 & +2.4 & +0.5 & / \\
\hline November & 1.8 & +3.4 & +0.6 & +0.8 & +2.7 & +2.4 & / \\
\hline December & -1.6 & +3.1 & -3.9 & +4.6 & +0.5 & +4.6 & / \\
\hline \multicolumn{8}{|c|}{ Precipitation $(\mathrm{mm})$} \\
\hline January & 59 & / & no data & no data & 17.8 & 25.8 & -23.3 \\
\hline February & 47 & I & no data & no data & 79.2 & -14.9 & 0.1 \\
\hline March & 56 & / & no data & no data & -17.4 & 11.7 & -9.1 \\
\hline April & 42 & / & +45 & +30 & +33 & -19 & +52 \\
\hline May & 58 & 1 & +15 & +62 & +16 & +65 & -19 \\
\hline June & 72 & / & +45 & +49 & -23 & +7 & +13 \\
\hline July & 73 & +78 & -19 & -11 & -52 & +109 & / \\
\hline August & 83 & +62 & +18 & +2 & +197 & +50 & I \\
\hline September & 94 & +142 & +25 & -26 & -69 & +188 & I \\
\hline October & 109 & +19 & +93 & +25 & +205 & -84 & / \\
\hline November & 94 & no data & no data & no data & 35.3 & -6 & / \\
\hline December & 66 & no data & no data & no data & -37.8 & -7.7 & 1 \\
\hline
\end{tabular}


Table 3. Lowest monthly soil temperature $\left({ }^{\circ} \mathrm{C}\right)$ from climate station at Ås and Rygge

\begin{tabular}{|c|c|c|c|c|}
\hline \multirow{2}{*}{ Year } & \multirow{2}{*}{ Month } & \multicolumn{3}{|c|}{ Depth $(\mathrm{cm})$} \\
\hline & & 20 & 50 & 100 \\
\hline \multicolumn{5}{|c|}{ Temperature $\left({ }^{\circ} \mathrm{C}\right)$} \\
\hline \multicolumn{5}{|c|}{ Ås station } \\
\hline \multirow{4}{*}{$\begin{array}{l}2011 / \\
2012\end{array}$} & November & 5.6 & 6.8 & 7.1 \\
\hline & December & 1.3 & 4.0 & 4.0 \\
\hline & January & 0.1 & l & 2.7 \\
\hline & February & -0.2 & l & 2 \\
\hline \multirow{6}{*}{$\begin{array}{l}2012 / \\
2013\end{array}$} & March & 0.1 & l & 1.8 \\
\hline & November & 2.2 & 4.0 & 5.8 \\
\hline & December & -0.4 & 0.9 & 2.5 \\
\hline & January & -2.9 & -0.1 & 1.5 \\
\hline & February & -1.5 & -0.2 & 1.2 \\
\hline & March & -2.9 & -0.6 & 0.7 \\
\hline \multicolumn{5}{|c|}{ Rygge station } \\
\hline \multirow{5}{*}{$\begin{array}{l}2013 / \\
2014\end{array}$} & November & 1.8 & 3.9 & 6.3 \\
\hline & December & 1.7 & 3.3 & 5.0 \\
\hline & January & 1.8 & 3.1 & 4.3 \\
\hline & February & 1.7 & 2.6 & 3.9 \\
\hline & March & 3.1 & 2.9 & 4.1 \\
\hline \multirow{5}{*}{$\begin{array}{l}2014 / \\
2015\end{array}$} & November & 3.9 & 6.1 & 8.0 \\
\hline & December & 0.3 & 2.5 & 4.7 \\
\hline & January & 0.3 & 2.2 & 3.7 \\
\hline & February & 0.7 & 2.0 & 3.2 \\
\hline & March & 1.6 & 2.8 & 3.6 \\
\hline \multirow{5}{*}{$\begin{array}{l}2015 / \\
2016\end{array}$} & November & 2.3 & 5.2 & 7.1 \\
\hline & December & 1.7 & 3.7 & 5.8 \\
\hline & January & 0.8 & 2.1 & 3.7 \\
\hline & February & 0.2 & 1.6 & 2.9 \\
\hline & March & 0.2 & 1.4 & 2.5 \\
\hline
\end{tabular}

Data for Ås: https://www.nmbu.no/fakultet/realtek/laboratorier/ bioklim/meteorologiske-data; Rygge: https://lmt.nibio.no/

The average annual temperature at Øsaker is $6.1^{\circ} \mathrm{C}$ and the average annual precipitation is $853 \mathrm{~mm}$. The winters at this location are unstable with alternating periods of freezing and thawing and several snow/melt events. Sub-zero temperatures commonly occur between December and March. During the research period it was warmer and wetter than usual for the most part (1961-1990) (Table 2).

Table 3 shows the soil temperature from the weather stations at Ås $\left(59^{\circ} 39^{\prime} \mathrm{N}, 10^{\circ} 46^{\prime} \mathrm{E}, 93 \mathrm{~m}\right.$ above sea level and Rygge ( $59^{\circ} 39^{\prime} \mathrm{N}, 10^{\circ} 75^{\prime} \mathrm{E}, 35 \mathrm{~m}$ above sea level). Even though the minimum air temperature in the area dropped to $-22.8^{\circ} \mathrm{C}$ (on 1 January 2016) during the research period (Table 2, daily values not shown), soil temperatures below freezing point were only registered in February $2012(20 \mathrm{~cm})$ and between January - March 2013 (20 and $50 \mathrm{~cm}$ depth).

Disturbed and undisturbed soil samples were taken from the subsoil at a 40 and $60 \mathrm{~cm}$ depth in the non-compacted plots ("reference P, M") and compacted plots ("compacted P, M") within one week in 2011. In 2016, samples were again taken from the compacted plots under both former ploughing treatments $(\mathrm{P})$ and minimum tillage (M) ("compacted M, P after 5 years") and compared to the non-compacted plots ("reference M, P") sampled in 2011. In order to determine the long-term effect of soil compaction, the sampling method remained constant between the sampling years.

The undisturbed samples (cylinder cores) were analysed in order to determine the pre-compression stress $(\mathrm{Pc})$, saturated hydraulic conductivity $\left(\mathrm{K}_{\mathrm{s}}\right)$, air permeability $\left(\mathrm{K}_{\mathrm{a}}\right)$, porosity parameters such as total pore volume (TP) and air capacity (AC) as well as the bulk density (BD). The number of samples (n) was 5 for AC and BD, 8 for Pc and $\mathrm{K}_{\mathrm{a}}$ and 9 for $K_{s}$ in 2011. In 2016 the number of samples was 8 for TP, AC, BD, Pc, $K_{a}$ and 9 for $K_{s}$.

Pre-compression stress, as described by Horn and Fleige (2009) and Wiermann et al. (2000), was derived from stress strain measurements carried out under confined conditions (undisturbed soil samples, volume $=236 \mathrm{~cm}^{3}$, diameter $=10 \mathrm{~cm}$ ). The samples were drained to $-6 \mathrm{kPa}$ matric potential using sand boxes with a hanging water column of $60 \mathrm{~cm}$. The matric potential gives information about the degree of water saturation in early spring (only widely coarse pores $>50 \mu \mathrm{m}$ are drained) as the lowest water-dependent soil strength (Zink et al., 2010). Pc was measured using a pneumatic multistep oedometer (uniaxial confined compression test) and eight load steps (20, 40, 60, 80, 100, 150, 300 and $400 \mathrm{kPa}$ ) (Peth et al., 2009). Each step lasted for two hours to allow for the drainage of excess pore water. The Pc values were determined graphically following the method of Casagrande (1936). $\mathrm{K}_{\mathrm{a}}$ was measured on the same soil cylinders used for Pc under steady-state flow conditions. A custom-made air permeameter was used consisting of a set of float-block flow meters (Key Instruments), which is described by Peth (2004). Saturated soil samples (volume $=100 \mathrm{~cm}^{3}$, diameter $=5.6 \mathrm{~cm}$ ) were used to determine $\mathrm{K}_{\mathrm{s}}$ based on the hood permeameter method described by (Hartge, 1993). Finally, the BD, TP and $\mathrm{AC}$ values (at $-6 \mathrm{kPa}$ ) were derived from the undisturbed soil samples (same size). BD was defined by the oven-dried soil mass $\left(105^{\circ} \mathrm{C}\right)$ per sample volume. Disturbed samples $(\sim 250 \mathrm{~g})$ were air-dried and sieved to $<2 \mathrm{~mm}$ for the analysis of the soil $\mathrm{pH}$ value (in $\mathrm{CaCl}_{2}$ solution), soil organic carbon content (coulometrically measured via dry combustion with a Ströhlein analytical device and multiplied by 1.72 to indicate the soil organic matter content, see Blume et al. (2010) and grain size distribution. The latter was 
determined using the combined sieve and pipette method (Hartge and Horn, 2009) with a texture classification following FAO guidelines (2006).

All samples for one plot (e.g. treatment ploughing) were taken in the same soil pit (2011: 4 pits representing treatments: "Reference (M, P)" and "Compacted (M, P)" and 2016: 2 pits representing the treatment "Compacted, after 5 years (M, P)". Due to the restricted area within the fields, no in-field replications were conducted. Repetitions were obtained by taking several samples within the same pit. The pits were placed randomly within plots. Statistics were obtained using 'General linear models' and 'Fisher tests' between samples and treatments in MINITAB 2018.

In order to define any negative effects on crop productivity which may be brought about by the impairment of one or several of the soil parameters which is expected to have negative effects on crop productivity, results from laboratory analyses were related to threshold values found in the literature (Lebert et al., 2007; Lebert et al., 2004). Based on this, Horn and Fleige (2009) defined AC, $\mathrm{K}_{\mathrm{a}}$ and $\mathrm{K}_{\mathrm{s}}$ as parameters with a high indication for subsoil compaction related to soil structure functionality, while other compaction-sensitive parameters such as BD and Pc only provide a low indication, because they only describe volume changes without considering the potentially negative impacts on pore functions. $\mathrm{AC}<5 \mathrm{vol} . \%, \mathrm{~K}_{\mathrm{s}}<10 \mathrm{~cm} \mathrm{~d}^{-1}$ (Lebert et al., 2004) and $\mathrm{K}_{\mathrm{a}}<48 \mathrm{~cm} \mathrm{~d}^{-1}$ (Horn and Fleige, 2009) are assumed to be threshold values which limit plant growth. Compaction-induced changes in pore volume were also evaluated as described by Pagliai and Vignozzi (2002) and Pagliai et al. (2004). The soil structure may be classified according to the total macroporosity (corresponding to $\mathrm{AC}$ representing the amount of air-filled pores $>50 \mu \mathrm{m}$ ), describing the soil as extremely porous (macroporosity $>40 \%$ ), porous $(25-40 \%)$, moderately porous $(10-25 \%)$, compact $(5-10 \%)$ and very compact $(<5 \%)$. The physical values were evaluated according to the 5 th edition of the German Soil Mapping Guidelines (Ad-hoc AG Boden, 2005) and Horn and Fleige (2003, 2009).

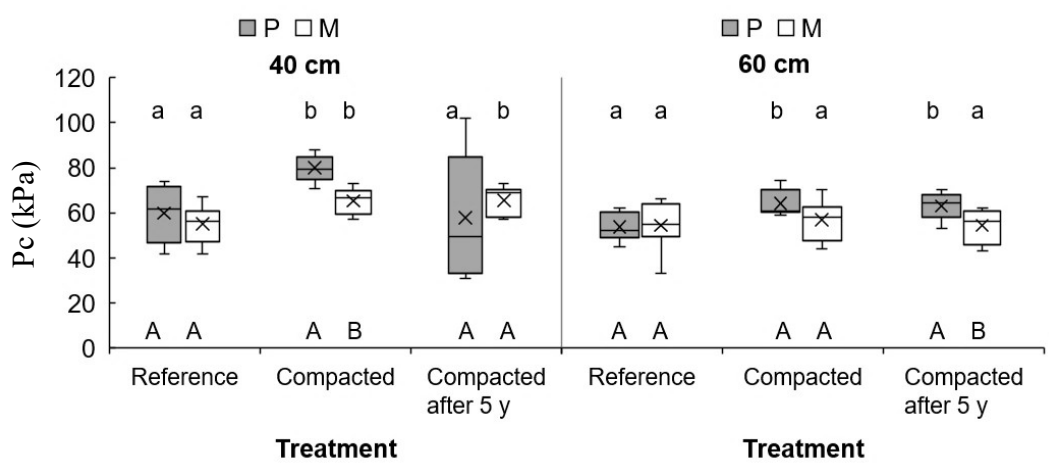

Fig. 2. Boxplots of the precompression stress values (Pc) of the non-compacted (reference) and compacted site (sampled in the same year) compared to the compacted site 5 years later for the 40 and $60 \mathrm{~cm}$ depths. $\mathrm{P}$ - ploughing, $\mathrm{M}$ - minimum tillage until compaction. Small letters indicate significant differences between the reference and compacted sites. Large letters indicate significant differences between treatments $\mathrm{P}$ and $\mathrm{M} . \mathrm{x}=$ arithmetic mean value, $-=$ median value.
The compaction verification tool (Horn and Fleige, 2009; Zink et al., 2011), is based on two highly indicative parameters, $\mathrm{AC}$ at $-6 \mathrm{kPa}$, with a critical value of $5 \mathrm{vol}$. \% and $\mathrm{K}_{\mathrm{s}}$ with a critical value of $10 \mathrm{~cm} \mathrm{~d}^{-1}$ (Lebert et al., 2007). If both values fall below their critical thresholds, damage to the soil is then defined as being potentially harmful. Soil status is classified according to CVT as: Class 1: Both $\mathrm{AC}$ and $\mathrm{K}_{s}$ are above their critical values (no harmful compaction), Classes II and III: only one parameter is below its limiting value (slightly harmful compaction), Class IV: both parameters are below their limiting values (harmful compaction). The CVT concept has been schematically illustrated by Zink et al. (2011) and Mordhorst et al. (2020).

For the CVT evaluation in 2011 and 2016, AC and $\mathrm{K}_{\mathrm{s}}$ values were sorted by size. The highest $\mathrm{K}_{\mathrm{s}}$ and $\mathrm{AC}$ values, the second-highest $\mathrm{AC}$ and $\mathrm{K}_{\mathrm{s}}$ values, etc., were used as pairs to evaluate the respective CVT class. Due to the variation in the sample number between the years (AC: $n=5$ in 2011, $\mathrm{n}=8$ in 2016), it was necessary to equalize the number of samples for $\mathrm{AC}$ and $\mathrm{K}_{\mathrm{s}}$ to its minimum number. Therefore, the values for 2011 were sorted by size and lowest and highest values were removed to obtain the same number of $\mathrm{AC}$ and $\mathrm{K}_{\mathrm{s}}$ values for the pairing of $\mathrm{K}_{\mathrm{s}}$ and $\mathrm{AC}$ for CVT evaluation. Thereafter, the highest $\mathrm{K}_{\mathrm{s}}$ and $\mathrm{AC}$ values, the second-highest $\mathrm{AC}$ and $\mathrm{K}_{\mathrm{s}}$ values etc., were paired to evaluate the respective CVT class.

\section{RESULTS}

Precompression stress (Pc) $40 \mathrm{~cm}$ depth: The Pc of both references (P, M) was classified as 'low'. Compaction led to significant increases by $33 \%$ (previous $\mathrm{P}$ treatment) and $18 \%$ (M treatment) compared to their non-compacted references, resulting in Pc values classified as 'medium' (Fig. 2). For the previous $\mathrm{P}$ treatment, the Pc value was significantly reduced (-28\%) 5 years after compaction when compared to the compacted state. For the previous M treatment, the 
Pc value remained almost unchanged after 5 years $(-4 \%$ compared to the initial state) but remained $19 \%$ higher than its initial state (reference $(\mathrm{M})$ ).

$60 \mathrm{~cm}$ depth: Compaction led to a significant increase in Pc for the former P treatment, also at the $60 \mathrm{~cm}$ depth $(+20 \%)$ which increased its Pc-classification from 'low' to 'medium' (Fig. 2). The Pc for the previous M treatment was classified as medium. After 5 years, the Pc for the compacted $P$ treatment remained almost unchanged $(-2 \%)$. The $\mathrm{Pc}$ for the $\mathrm{M}$ treatment was not changed significantly by compaction $(+5 \%)$ or after five years $(-5 \%)$. The initial Pc state (non-compacted Reference) was reached under the $\mathrm{M}$ treatment, but under the $\mathrm{P}$ treatment it remained $17 \%$ higher than its initial state.

Bulk density (BD) $40 \mathrm{~cm}$ depth: For the non-compacted Reference the mean $\mathrm{BD}$ values were classified as 'medium' under both tillage treatments (M, P) (Fig. 3). Compaction increased $\mathrm{BD}$ most for the $\mathrm{M}$ plot ( $\mathrm{P}$ plot: $+3 \%$, M plot: $+12 \%$ ) resulting in $\mathrm{BD}$ being classified as 'high' (Ad-hoc-AG Boden, 2005). Although not significant, BD was reduced five years after compaction (P: $-3 \%$, M: $-4 \%$ compared to the compacted state), especially under the $\mathrm{P}$ treatment where it reached the initial state (reference (P)). By contrast, after five years, the BD under M tillage remained $8 \%$ higher than the initial state (reference $(M)$ ).
$60 \mathrm{~cm}$ depth: Wheel impact also increased $\mathrm{BD}$ slightly at the $60 \mathrm{~cm}$ depth, especially for the P treatment (P: $+5 \%$, M: $+1 \%$ ) (Fig. 3), but was still classified as 'medium'. Although not significant, the BD value was slightly reduced during the five years of the $\mathrm{P}$ treatment $(-1 \%)$. The initial state was only regained for the $\mathrm{M}$ treatment (reference $(\mathrm{M})$ ), while $\mathrm{BD}$ under the $\mathrm{P}$ treatment remained $4 \%$ higher compared to the reference (P). In summary, compaction had a significantly greater effect on the $M$ than on the $P$ treatment at a $40 \mathrm{~cm}$ depth, which was still identifiable 5 years after compaction.

Air capacity (AC) $40 \mathrm{~cm}$ depth: The AC for both references $(\mathrm{P}, \mathrm{M})$ were classified as 'medium' (Ad-hoc-AG Boden 2005), while compaction decreased AC further under the $\mathrm{P}$ treatment $(-60 \%)$. These values fell below the threshold value of $<5$ vol. \% (Lebert et al., 2007), while the majority of values for the $\mathrm{M}$ treatment remained in the 'medium' range. By contrast, $\mathrm{AC}$ was not impaired by compaction in the $\mathrm{M}$ treatment and even increased slightly $(+12 \%)$. During the five-year experimental period, AC significantly increased for both the $\mathrm{P}(+161 \%$ compared to compacted state) and $M$ treatment $(+29 \%)$. After 5 years, the initial AC (reference P, M) was exceeded, irrespective of tillage treatment ( $\mathrm{P}:+5 \%, \mathrm{M}:+44 \%)$ as the 'medium' $\mathrm{AC}$ values indicate (Fig. 4).

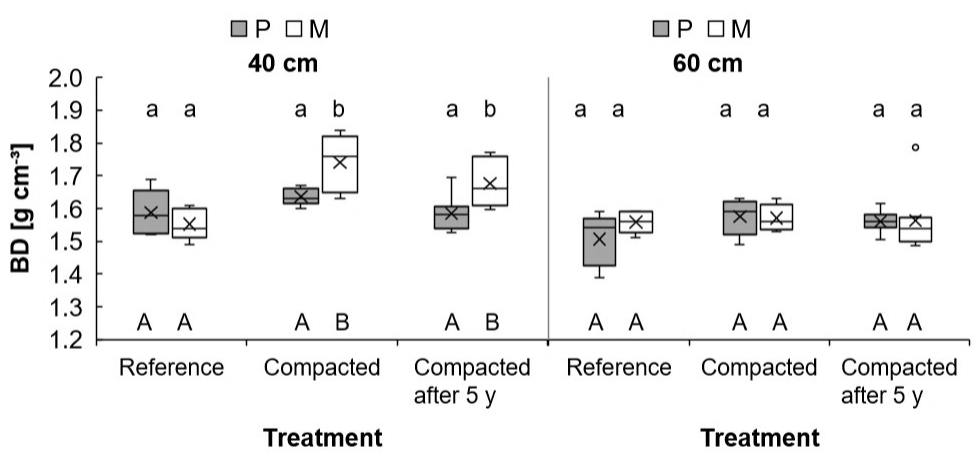

Fig. 3. Bulk density (BD) of the non-compacted (reference) and compacted site (sampled in the same year) compared to the compacted site 5 years later at the 40 and $60 \mathrm{~cm}$ depths. Explanations as in Fig. 2.

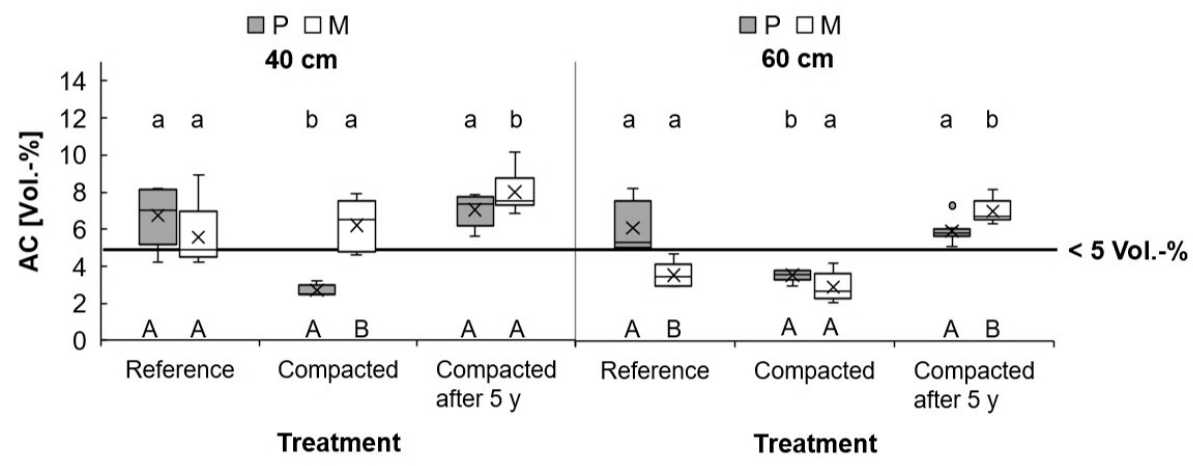

Fig. 4. Air capacity (AC, pores $>50 \mu \mathrm{m}$ ) of the non-compacted (Reference) and compacted site (sampled in the same year) as compared to the compacted site 5 years later for the 40 and $60 \mathrm{~cm}$ depths. Limiting value $<5$ vol. \% according to Lebert et al. (2007). Explanations as in Fig. 2. 
$60 \mathrm{~cm}$ depth: Compaction led to a significant decrease in $\mathrm{AC}$ for the $\mathrm{P}$ treatment ( $-42 \%)$, which corresponds to a change from 'compact' (medium) to very compact ('low' AC) compared to the reference (P) (Fig. 4). In this plot AC fell below its threshold value of 5 vol. \%. Over the five-year experimental period, the $\mathrm{AC}$ value of the $\mathrm{P}$ treatment increased significantly $(+67 \%)$ so that the initial state (reference $(\mathrm{P})$ ) was regained. For the $\mathrm{M}$ treatment, $\mathrm{AC}$ was described as 'low' in the non-compacted state (reference (M)) and decreased further (-18\%) due to compaction (compacted (M)). However, after five years AC was recovered significantly $(+140 \%$, which corresponds to an increase in $\mathrm{AC}$ from 'very compact' ('low') to 'compact' ('medium')) thereby representing a higher AC value than both the initial state (reference (M)) and all plots of the P treatment.

Compaction had a significantly greater negative effect on $\mathrm{AC}$ for the $\mathrm{P}$ treatment than for the $\mathrm{M}$ treatment at both $40 \mathrm{~cm}$ and $60 \mathrm{~cm}$ depths, while the recovery of AC five years after compaction was most apparent under the $\mathrm{M}$ treatment, especially at $60 \mathrm{~cm}(+96 \%$ compared to Reference $(\mathrm{M}))$.

Air permeability $\left(\mathrm{K}_{\mathrm{a}}\right) 40 \mathrm{~cm}$ depth: Non-compacted $R$ plots showed 'low' $K_{a}$ values (Horn and Fleige, 2003) irrespective of the previous tillage treatment of $\mathrm{M}$ and $\mathrm{P}$ (Fig. 5). Compaction led to a significant reduction in $\mathrm{K}_{\mathrm{a}}$ for both treatments (P -41\%, M - $62 \%$ ) compared to the
Reference (P; M). In the $\mathrm{M}$ treatment, $\mathrm{K}_{\mathrm{a}}$ fell below the threshold value of $<48 \mathrm{~cm} \mathrm{~d}^{-1}$ indicating a 'very low' value. It increased again after 5 years $(\mathrm{P}:+63 \%, \mathrm{M}:+112 \%)$, almost reaching its initial state (reference $(\mathrm{P})$, while the $\mathrm{M}$ treatment still remained reduced $(-20 \%)$ compared to its reference $(\mathrm{M})$.

$60 \mathrm{~cm}$ depth: While $\mathrm{K}_{\mathrm{a}}$ was already 'very low' and below its limiting value of $<48 \mathrm{~cm} \mathrm{~d}^{-1}$ for both references $(\mathrm{P}, \mathrm{M})$, compaction reduced $\mathrm{K}_{\mathrm{a}}$ still further, mainly for the $M$ treatment (P: -26\%, M: -65\%) (Fig. 5). During the fiveyear period after compaction it increased again by $130 \%$ and $669 \%$ for $\mathrm{P}$ and $\mathrm{M}$, respectively, compared to the compacted state. The $\mathrm{K}_{\mathrm{a}}$ of the initial state (reference $\mathrm{P}, \mathrm{M}$ ) was even exceeded for both the $\mathrm{P}(+71 \%)$ and $\mathrm{M}$ treatment $(+170 \%)$, but still remained at a 'very low' level.

Saturated hydraulic conductivity $\left(\mathrm{K}_{\mathrm{s}}\right) 40 \mathrm{~cm}$ : The $\mathrm{K}_{\mathrm{s}}$ value of the $R$ plots was classified as 'medium' (P) and 'low' (M). No significant effects of compaction were found for $\mathrm{K}_{\mathrm{s}}$. Compaction only reduced $\mathrm{K}_{\mathrm{s}}$ marginally in the $\mathrm{P}$ treatment resulting in a 'low' $\mathrm{K}_{\mathrm{s}}$ value $(-51 \%$ compared to the reference $(\mathrm{P})$ ), which is below its threshold value of $10 \mathrm{~cm} \mathrm{~d}^{-1}$ (Lebert et al., 2007). After five years, $\mathrm{K}_{\mathrm{s}}$ for the $P$ treatment increased $(+123 \%$ compared to the compacted state) and exceeded its initial value (reference $(\mathrm{P}))(+9 \%)$, which was classified as 'medium' (Fig. 6). The $\mathrm{K}_{\mathrm{s}}$ value of

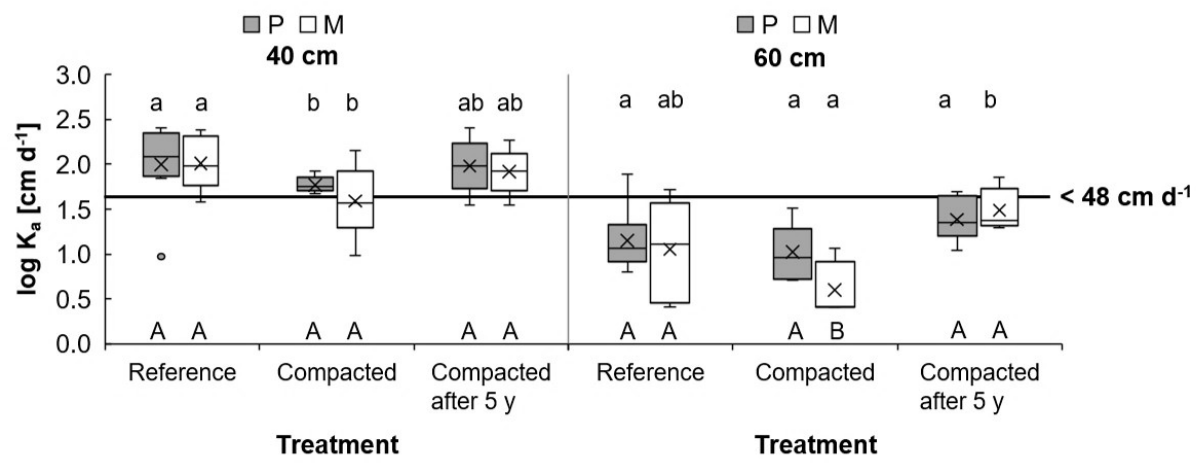

Fig. 5. Air permeability $\left(\mathrm{K}_{\mathrm{a}}\right)$ of the non-compacted (reference) and compacted site (sampled in the same year) compared to the compacted site 5 years later for the 40 and $60 \mathrm{~cm}$ depths. Limiting value $<48 \mathrm{~cm} \mathrm{~d}^{-1}$ according to Horn and Fleige (2009). Explanations as in Fig. 2.

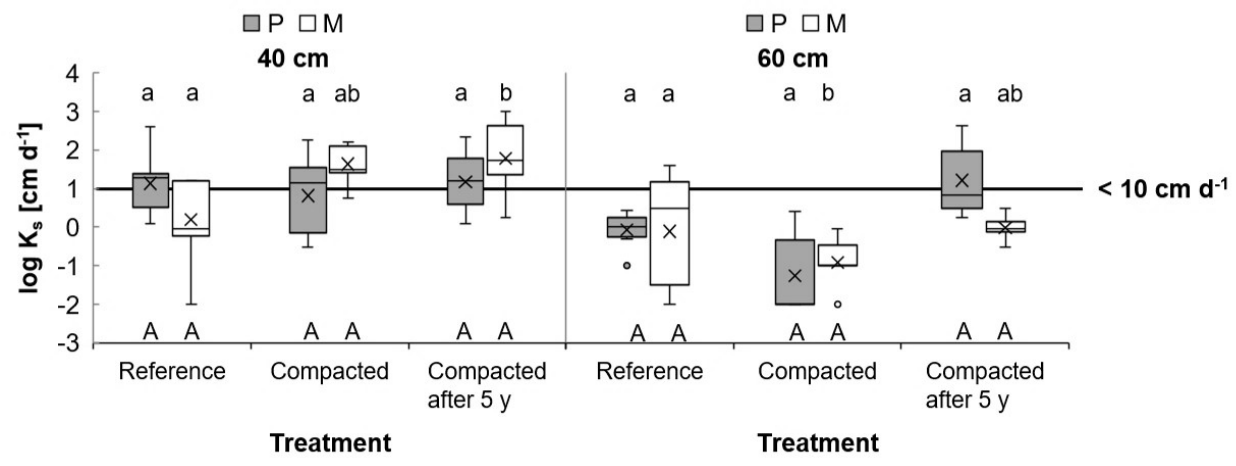

Fig. 6. Saturated hydraulic conductivity $\left(\mathrm{K}_{\mathrm{s}}\right)$ of the non-compacted (reference) and compacted site (sampled in the same year) as compared to the compacted site 5 years later for the 40 and $60 \mathrm{~cm}$ depths. Limiting value $<10 \mathrm{~cm} \mathrm{~d}^{-1}$ according to Lebert $e$ al . (2007). Explanations as in Fig. 2. 
the reference (M) was below its threshold value, but was greatly increased by compaction from the 'low' to 'medium' values $(+2689 \%)$ possibly due to its very low initial value (Fig. 6). In the $M$ treatment the $\mathrm{K}_{\mathrm{s}}$ value increased more during the five-year experimental period $(+41 \% \mathrm{com}-$ pared to the compacted state).

$60 \mathrm{~cm}$ depth: The $\mathrm{K}_{\mathrm{s}}$ values of the reference $(\mathrm{P}, \mathrm{M})$ were at a 'very low' level at $60 \mathrm{~cm}$ under both of the previous tillage treatments (Fig. 5). Compaction reduced both values further, to a significant extent in the case of the $M$ treatment (P: $-41 \%, \mathrm{M}:-87 \%$ ), as compared to their references. After five years, the $\mathrm{K}_{\mathrm{s}}$ value was greatly exceeded especially under the $\mathrm{P}$ treatment $(\mathrm{P}:+3098 \%, \mathrm{M}:+869 \%)$ as compared to the compacted state (non significant - n.s.). For both treatments $(\mathrm{P}, \mathrm{M})$ the initial value (reference $\mathrm{P}$, M) was exceeded (P: $+1798 \%$, M: $+24 \%$ ) (n.s.), while only the mean $\mathrm{K}_{\mathrm{s}}$ value for the $\mathrm{P}$ treatment was above its limiting value, thereby representing a 'medium' level (Fig. 6). No significant differences between the $\mathrm{P}$ and $\mathrm{M}$ treatments were found.

The compaction verification tool (CVT) was used to evaluate the compaction effect and its regeneration of the soil structure five years after compaction.

$40 \mathrm{~cm}$ depth: Directly after compaction, $40 \%$ of the samples were classified as 'harmfully compacted' under the former P treatment. Five years later $50 \%$ of the samples were classified as 'slightly harmfully compacted' (class II), while the remainder were in class I, classified as 'not harmfully compacted' (Fig. 7A).

The $\mathrm{M}$ treatment was less affected by compaction, with only $20 \%$ of the samples classified as 'slightly harmfully compacted' and the majority of the samples $(80 \%)$ clas- sified as 'not harmfully compacted'. Five years later, the proportions were $13 \%$ (slightly harmfully compacted), and $87 \%$ (not harmfully compacted (Fig. 7A)).

$60 \mathrm{~cm}$ depth: Directly after compaction, the P treatment was classified as 'harmfully compacted' (class IV). After five years, much of this harmful compaction had diminished, with $63 \%$ of samples indicating only 'slight harmful compaction' (class II) and 37\% of samples indicating 'no harmful compaction' (Fig. 7B).

The $\mathrm{M}$ treatment was also classified as 'harmfully compacted' directly after compaction. After five years, all values of the $M$ treatment were improved to some extent and could therefore be evaluated as being only 'slightly harmfully compacted' (class II).

\section{DISCUSSION}

The references $(\mathrm{P}, \mathrm{M})$ were not additionally compacted during the compaction event of 2011, but these soils were under arable cultivation for many decades, meaning that the plots had been wheel impacted many times during the years prior to the compaction experiment. As Pc values are a result of the individual stress history of a soil (Alakukku et al., 2003), they also include the effects of previous soil compaction. The Pc values for the two references (P, M) at both the $40 \mathrm{~cm}$ and $60 \mathrm{~cm}$ depth were classified as low (Fig. 2), which indicates that the subsoil of these clay soils is unstable at field capacity ( $-6 \mathrm{kPa})$. It has been shown that soil tillage and wheel impact modify the physical properties of the soil (Gomez et al., 1999; Raper, 2005; Wiermann and Horn, 2000). Since tillage did not directly affect the soil structure in the subsoil, changes to the physical parameters at depths of 40 and $60 \mathrm{~cm}$ may be explained by shearing-

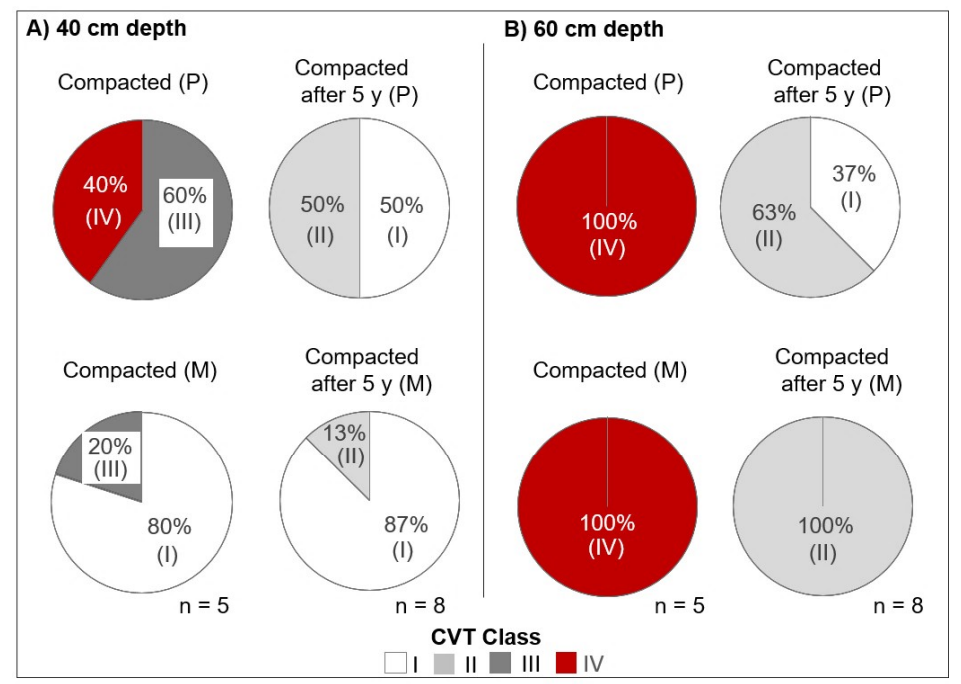

Fig. 7. Compaction verification tool (CVT) for evaluating the compaction state directly after compaction and five years later at the $40 \mathrm{~cm}$ (A) and $60 \mathrm{~cm}$ depths (B). P - ploughing, $\mathrm{M}$ - minimum tillage. The diagram shows air capacity (AC) in relation to hydraulic conductivity $\left(\mathrm{K}_{\mathrm{s}}\right)$. CVT is calculated based on the threshold values of $5 \mathrm{vol} . \%$ for AC and $10 \mathrm{~cm} \mathrm{~d}^{-1}$ for $\mathrm{K}_{\mathrm{s}}$. Class $\mathrm{I}$ : Both, AC and $\mathrm{K}_{\mathrm{s}}$ are above their critical values (no harmful compaction), Classes II ( $\mathrm{K}_{\mathrm{s}}$ impaired) and III (AC impaired): only one parameter is above its limiting value (slight harmful compaction), Class IV: both parameters below their limiting values (harmful compaction). 
induced kneading through the application of tillage during periods of high water content in early spring time which results in a weak soil structure (Horn et al., 2003; Wiermann et al., 2000). However, a comparison between the $\mathrm{P}$ and $M$ reference plots in this study reveals no significant differences in the subsoil (Figs 2-6), but some values e.g. Pc (Fig. 2) and BD (Fig. 3) on the P plot indicate that the initial state of the soil (reference $(\mathrm{P} ; \mathrm{M})$ ) was more compacted at the $40 \mathrm{~cm}$ than at the $60 \mathrm{~cm}$ depth. This may be due to a plough pan caused by many years of ploughing down to $30 \mathrm{~cm}$, which is common in Norwegian cereal production on this type of soil (Seehusen et al., 2014a, 2014b).

Previous studies conducted on the same site show that minimum tillage leads to a higher degree of stability in the upper soil horizon and previous findings reveal a $74 \%$ higher Pc value in the upper soil layer $(20 \mathrm{~cm}$ depth) of the reference (M) compared to reference (P) (Seehusen et al., 2014b). Minimum tillage led to a less pronounced, but significant, increase in Pc compared to the $P$ treatment which is in accordance with the results of studies by Wiermann and Horn (2000) and Zink et al., (2010) who demonstrated that minimally tilled soils are less susceptible to compaction.

Due to this more stable soil structure in the upper soil layer, there is a tendency for the subsoil of the $\mathrm{M}$ treatment to be less effected by compaction compared to the $\mathrm{P}$ treatment, as the results for $\mathrm{Pc}, \mathrm{AC}$, and $\mathrm{K}_{\mathrm{s}}$ (Figs 2, 4, 6) illustrate. The corresponding CVT showed no harmful compaction at $40 \mathrm{~cm}$ for the $\mathrm{M}$ treatment (Fig. 7A). By conrast, the parameters $\mathrm{AC}, \mathrm{K}_{\mathrm{a}}$ and $\mathrm{K}_{\mathrm{s}}$ were found to be below their critical values even for the reference (M) at a $60 \mathrm{~cm}$ depth, which may also be explained by the natural compaction due to a high clay content at this depth. As the stagnic, clay-enriched $2 \mathrm{Cg}$ horizon ( $46 \%$ clay, Table 1) already begins at $50 \mathrm{~cm}$ under the $\mathrm{M}$ treatment (compared to 80 $\mathrm{cm}$ for the reference soil under the $\mathrm{P}$ treatment), the high compaction state at the $60 \mathrm{~cm}$ depth results from geogenic processes, which exceed the tillage effect.

All of the plots were ploughed each year $(25 \mathrm{~cm})$ after compaction, this was mainly due to improved plant growth, which was negatively affected by both soil compaction and weed infestation. Soil tillage, especially ploughing is commonly assumed to effectively loosen up soil compaction (Appel, 2012; Batey, 2009).

Although performed under workable conditions (Seehusen et al., 2014b), our results show that the compaction event negatively affected nearly all soil parameters at depths of both $40 \mathrm{~cm}$ and $60 \mathrm{~cm}$. Such compaction induced changes are in agreement with previous results from the same site (Seehusen et al., 2014a). This finding also supports other studies which show that soil compaction may also alter soil structure (Batey, 2009) at $>50 \mathrm{~cm}$ soil depth (Pulido-Moncada et al., 2019; Zink et al., 2011). This is especially true for parameters with a high indication of soil functionality such as $\mathrm{AC}, \mathrm{K}_{\mathrm{a}}$ and $\mathrm{K}_{\mathrm{s}}$. If the induced stresses exceed the Pc of a soil, as shown by the compaction treat- ment in this study (Seehusen et al., 2014b), this may lead to a breakup in the compacted structural units and also to a partial loosening of the soil as shown by Wiermann et al. (2000) for the plough pan. This result was obtained previously on the same plot (Seehusen et al., 2014a) and may explain the increase in $\mathrm{AC}$ and $\mathrm{K}_{\mathrm{s}}$ under the previous $\mathrm{M}$ treatment at a $40 \mathrm{~cm}$ depth (Figs 4 and 6). Ploughed topsoils were reported to contain many large but unstable macropores (Rasmussen, 1999; Seehusen et al., 2014a) but the deterioration in transport function $\left(\mathrm{K}_{\mathrm{s}}, \mathrm{K}_{\mathrm{a}}\right)$ due to compaction is often linked to the loss of the most unstable macropores (Horn et al., 2003; Kim et al., 2010; Peth et al., 2010). With regard to the subsoil, $A C$ and $K_{s}$ even increased in the compacted plots under $\mathrm{M}$ treatment as compared to the reference (M) (Fig 4 and 6). It has been shown that large, vertical pores tend to be less sensitive to compaction (Pulido- Moncada et al., 2019; Zhai and Horn, 2019). This suggests, that more structural pores were preserved and that more new ones were formed in the $\mathrm{M}$ compared to the $\mathrm{P}$ treatment. Also, Wiermann et al., (2000) found that more macropores remained stable after compaction in the subsoil $(>30 \mathrm{~cm})$ under conservation as opposed to conventional tillage, thereby supporting the greater potential of structural regeneration by physical and biological processes under the former method.

The higher clay content (46\%) of the reference (M) as opposed to the reference (P) with $32 \%$ clay at a $60 \mathrm{~cm}$ depth may have influenced the compaction (Håkansson et $a l ., 1987)$ and thereby explain the finding that the previous $\mathrm{M}$ treatment was more compacted at $60 \mathrm{~cm}$ than the $\mathrm{P}$ treatment. A high clay content may also mask the effects of further compaction as shown previously (Seehusen et al., 2014a). This may also have caused a less pronounced regeneration effect at the $60 \mathrm{~cm}$ depth on the compacted (M) as compared to the compacted (P) during the 5 years of the study as shown by the CVT (Fig. 7B). It has been documented previously, that a further development of initial vertical cracks requires a more intense drying than before. This also increases the mechanical soil strength due to strengthening of the matric potential (Peng and Horn, 2007).

Results from this study show that several parameters were regenerated and reached their initial state (reference $(\mathrm{P}, \mathrm{M})$ ) during the five-year research period, especially for the previous M treatment (Figs 2-6). Several parameters even exceeded their initial values, such as $\mathrm{AC}$ and $\mathrm{K}_{\mathrm{s}}$ under both tillage treatments. At a $60 \mathrm{~cm}$ depth $\mathrm{AC}, \mathrm{K}_{\mathrm{s}}$ and $\mathrm{K}_{\mathrm{a}}$ were also regenerated under both tillage systems and partly exceeded their critical ranges $\left(\mathrm{AC}>5\right.$ vol. $\%, \mathrm{~K}_{\mathrm{s}}>10$ $\mathrm{cm} \mathrm{d}^{-1}$ ), indicating no further harmful subsoil compaction (Fig. 7A, B). These results do not completely agree with studies that describe subsoil compaction as very long-lasting with few mechanisms for the natural amelioration of soil compaction in deeper soil layers (Berriso et al., 2012; Håkansson and Reeder, 1994). Therefore a description of the shear induced kneading of the soil during tillage which 
coincided with partial homogenization should be included in order to explain the initial cracking induced coarsening of the pore volume by a few new vertical cracks. Thus, the natural processes following the more intense damaging of the soil structure were causal for the structural regeneration effect in the subsoil. These natural processes are discussed in the following:

In soils with a high clay content, annual freezing and thawing may decrease soil compaction in the upper soil layer $(<30 \mathrm{~cm})$ which is equally as effective as soil tillage (Jabro et al., 2014; Wang et al., 2020a). Other studies that were performed on topsoils with a similar clay content as the one examined in our study show that annual freezing-thawing increases pore space, reduces bulk density and aggregate stability and also increases the porosity and hydraulic conductivity (Gameda et al., 1987; Jabro et al., 2014; Kværnø and Øygarden, 2006; Rasmussen, 1999; Wang et al., 2020a; Wang et al., 2020b). A study has revealed a $59 \%$ reduction in penetration resistance on a compacted clay soil at a $20-30 \mathrm{~cm}$ depth due to freezing and thawing (Jabro et al., 2014). The same trend was observed for macroporosity with increases of up to $388 \%$ (Wang et al., 2020a) due to the freezing and thawing of compacted clay soils in the upper soil layer $(0-25 \mathrm{~cm}$ depth).

The duration of the seasonal and repeated freeze-thaw period is on average 100 days from December until March (Table 2) in this area of Norway. Despite the low air temperature observed during the winter periods (Table 2) with the coldest temperature (measured on January 1st 2016) of $-22.8^{\circ} \mathrm{C}$ (data not shown), almost no soil temperatures below zero were registered during most of the research study (Table 3 ). This may be mainly due to snow cover during longer periods, which insulates the soil surface and reduces the freezing of the soil. The study area in Norway is characterized by unstable soil temperatures which may be a reason for the potentially great number of freezing and thawing cycles as reported previously (Kværno and Øygarden, 2006). This was also reflected in the daily variation in soil temperatures during the research period (data not shown). Climate change in Norway is expected to lead to shorter and milder winters which may further increase both the number and extent of freezing and thawing cycles in the future (Hanssen-Bauer et al., 2015; Kværno and Øygarden, 2006). This may support soil loosening through freezing in the future (Jabro et al., 2014).

Especially during the growing season, the soil was exposed to several wet and dry periods (Table 2). In soils with a high clay content, drying leads to shrinkage which primary causes vertical cracks (Fig. 1) that may reach into the subsoil. These cracks decrease the soil volume and they are an important pathway for water infiltration, aeration and root growth. These processes are closely related to the recovery of e.g. porosity after soil compaction and contribute to soil loosening (Bamgbopa, 2016; Dexter, 1988; Dexter, 1991; Jabro et al., 2014). Even though the influence of these natural factors may be more intensive in the upper soil layer, our results indicate a regeneration of $A C, K_{s}$ and $\mathrm{K}_{\mathrm{a}}$, at the 40 and $60 \mathrm{~cm}$ depths under both treatments (M and P) five years after compaction (Figs 2-6). Drying may lead to cracks in the soil but not loosen up soil aggregates (intra-aggregate pore volume (Horn and Smuker, 2005)), which will still be compacted (Bruand et al., 2001). This finding agrees with our data that show a several times higher improvement in the values of $K_{a}, K_{s}$ and $A C$ (due to the increase in inter-aggregate pore volume) than $\mathrm{BD}$ which represents the total soil matrix (inter- and intra-aggregate pore volume) (Figs 3-6).

Shrinkage is locally variable, but Peth et al. (2010) demonstrated that it occurs predominantly in the vicinity of pre-existing cracks, which may result in a network of secondary cracks (Bamgbopa, 2016). Hence, the preservation of conductible macropores (higher $\mathrm{AC}$ and $\mathrm{K}_{\mathrm{s}}$ ) for the M compared to the $P$ treatment at a $40 \mathrm{~cm}$ depth may possibly have supported a more intensive structural regeneration due to drying and wetting cycles in the compacted plots over the course of 5 years.

As these fields were under cultivation it may be expected that the plant roots of barley (Hordeum vulgare L.), which may reach a root depth of up to $2 \mathrm{~m}$ (Entrup and Oehmichen, 2006), had an influence on the soil structure during the research period. Plant roots may alter soil structure by pushing aside soil particles or induce a shrinkage processes through the effects of hydraulic stresses from root water uptake and thereby create new pores which may affect both hydraulic conductivity and gas flow (Dexter, 1991; Löfkvist, 2005). Plant roots may thereby also loosen up the soil at a greater depth (Cresswell and Kirkegaard, 1995) and improve both aggregation and soil stabilization (Hallett et al., 2003) which may also contribute to a portion of the regeneration shown in our data.

Although soils with a high clay content as it was the case with this study (Table 1) may be an unfavourable habitat (Duiker and Stehouwer, 2008), earthworms were found at a $30 \mathrm{~cm}$ depth (data not shown) while soil sampling. These earthworms are expected to have a pronounced effect on soil structure and loosen up the soil over time (Dexter, 1991; Hallett et al., 2003).

The CVT shows the regenerative effect of $A C$ and $\mathrm{K}_{\mathrm{s}}$ through the change from class IV (harmfully compacted) at a $60 \mathrm{~cm}$ depth (and $40 \mathrm{~cm}$ in the P plot) to class II (slightly harmfully compacted) (Fig. 7 A, B). While class IV implies a harmful compaction and the need to change land use practice (Raper, 2005), class II is theoretically classified as less harmfully compacted (Zink et al., 2011). Class II implies that $\mathrm{K}_{\mathrm{s}}$ is impaired. Due to its importance for water infiltration through the soil profile, and down to the drain pipes, $K_{\mathrm{s}}$ has been classified as a high indication value for soil compaction (Horn and Fleige, 2009). Restricted water infiltration is the most adverse effect of soil compaction in wet climates (Batey, 2009) since it increases the risk of flooding and water erosion as well as soil and nutrient loss 
(Keller et al., 2019; Rogger et al., 2017). This may affect crop production but also have a detrimental effect (e.g. eutrophication) on the ecosystem itself (Horn and Fleige, 2009). These authors also recommended an increase in the critical value to 8 vol. \% for hydromorphic soils (Table 1) to guarantee sufficient oxygen availability. By this standard, adequate $\mathrm{AC}$ values were only achieved after 5 years under minimal tillage.

Ponding water and wet soils may reduce workability and thereby either shorten the growing season, delay the harvest, reduce yields and quality (Sogn and Hauge, 1976) or promote further compaction. After 5 years, $K_{s}$ is still reduced (class II) at a $60 \mathrm{~cm}$ depth especially on the compacted plots (M), assuming that the regeneration effect is limited to a naturally compacted clay horizon. Although contemporary rainfall intensity seldom exceeds $1 \mathrm{~cm} \mathrm{~h}^{-1}$ (Manen et al., 2011), climate change in Norway is predicted to cause both higher total precipitation but also more incidents of substantial rainfall (Hanssen-Bauer et al., 2015). Hence, the limited $\mathrm{K}_{\mathrm{s}}$ value in the subsoil is expected to become more problematic in the future (Keller et al., 2019).

Finally, our findings agree with the studies by Etana and Håkansson (1994) which showed that even 11 years after compaction, yields were still reduced despite annual freezing down to depths of $40-70 \mathrm{~cm}$ which indicates that neither wetting/drying cycles nor annual freezing/thawing may be sufficient to restore infiltration rates to precompaction levels and loosen up the subsoil compaction completely (Batey, 2009; Gameda et al., 1987).

The fields used in the study were under cultivation for many decades which may explain the comparatively low parameters (e.g. AC, $\mathrm{K}_{\mathrm{s}}$ ) of the references $(\mathrm{P}, \mathrm{M})$ compared to the assumed threshold values for plant growth (Figs 4, 6). These parameters (at $40 \mathrm{~cm}$ ) are for the most part in agreement with the findings from a nearby field with similar soil and the same tillage regime (unpublished). This study demonstrates the potential regeneration effect of clayey soils under given climate conditions, but it should also be considered that during the research period, further compaction of the research field was avoided. In terms of practical farming techniques this practice is probably unrealistic because if a farmer uses machinery as heavy (total weight $36 \mathrm{Mg}$ ) as the one used in the compaction experiment, this machinery is likely to be used on a regular basis. This would cause additional, cumulative compaction (Chamen et al., 2003; Håkansson and Reeder, 1994) and reduce the potential for the regeneration of compacted subsoils.

\section{CONCLUSIONS}

1. Multiple wheel impacts with high wheel loads lead to soil compaction in the deeper soil layers.

2 . The results show that such compaction may be ameliorated, at least to some extent over time through the effects of natural factors such as freeze-thaw cycles and most especially by swelling-shrinking cycles as well as by the effects of root growth.
3. The restoration of soil structure on this clay soil is still incomplete and remains in a weak transitional stage after five years. Hence, the possibilities for the natural amelioration of soil compaction in the subsoil are limited while, under practical conditions at a farm level, further soil deformation due to soil management, which is not site-adjusted, is feasible.

4. The avoidance of soil compaction therefore remains at the highest priority level under Northern climate conditions, in order to maintain adequate soil function.

5. Further research should be performed concerning the possibilities of ameliorating soil compaction through biological and mechanical measures.

Conflict of interest: The authors declare no conflict of interest.

\section{REFERENCES}

Ad-hoc-AG Boden, 2005. Bodenkundliche Kartieranleitung (5 Auflage). Bundesanstalt für Geowissenschaften und Rohstoffe, Hannover.

Alakukku L., Weisskopf P., Chamen W.C.T., Tijink F.G.J., van der Linden J.P., Pires S., Sommer C., and Spoor G., 2003. Prevention strategies for field traffic-induced subsoil compaction: a review Part 1. Machine/soil interactions. Soil Till. Res., 73, 145-160.

https://doi.org/10.1016/s0167-1987(03)00107-7

Appel T., 2012. Boden-Bearbeitungssysteme im Fokus von Ökonomie und Ökologie. Landwirtschaftskammer und der Landesregierung Rheinland-Pfalz.

Aune B.D.K., 1993. DNMI Climate Temperature Norms (in Norwegian). Norwegian Meteorological Institute, Oslo, Norway.

Bamgbopa O.S., 2016. Investigation of shrinkage and cracking in clay soils under wetting and drying cycles. Int. J. Eng. Res. Technol., 5, 283-319. https://doi.org/10.17577/ijertv5is110183

Batey T., 2009. Soil compaction and soil management - a review. Soil Use Manag., 25, 335-345. https://doi.org/10.1111/j.1475-2743.2009.00236.x

Berriso F.E., Schjønning P., Keller T., Lamande M., Etana A., de Jonge L.W., Iversen B.V., Arvidsson J., and Forkman J., 2012. Persistent effects of subsoil compaction on poresize distribution and gas transport in a loamy soil. Soil Till. Res., 122, 42-51. https://doi.org/10.1016/j.still.2012.02.005

Blume H.P., Stahr K., and Leinweber P., 2010. Bodenkundliches Praktikum. Spektrum Akademischer Verlag, Heidelberg, Germany. https://doi.org/10.1007/978-3-8274-2733-5_5

Bruand A., Cochrane H., Fisher P., and Gilkes R.J., 2001. Increase in the bulk density of a grey clay subsoil by filling of cracks by topsoil. Eur. J. Soil Sci., 52, 37-47. https://doi.org/10.1046/j.1365-2389.2001.t01-1-00365.x

Casagrande A., 1936. The determination of preconsolidation load and its practical significance. In: Int. Conf. Soil Mechanics and Foundation Engineering. 60-64, Harvard University, Cambridge, MA, USA.

Chamen T., Alakukku L., Pires S., Sommer C., Spoor G., Tijink F., and Weisskopf P., 2003. Prevention strategies 
for field traffic-induced subsoil compaction: a review Part 2. Equipment and field practices. Soil Till. Res., 73, 161174. https://doi.org/10.1016/s0167-1987(03)00108-9

Cresswell H.P., and Kirkegaard J.A., 1995. Subsoil amelioration by plant roots- the process and and the evidence. Aust. J. Soil. Res., 33, 221-239. https://doi.org/10.1071/sr9950221

Dexter A.R., 1988. Advances in characterization of soil structure. Soil Till. Res., 11, 199-238. https://doi.org/10.1016/0167-1987(88)90002-5

Dexter A.R., 1991. Amelioration of soil by natural processes. Soil Till. Res., 20, 87-100. https://doi.org/10.1016/0167-1987(91)90127-j

Duiker S. and Stehouwer R., 2008. Earthworms. Pennsylvania State University, USA.

Entrup N.L. and Oehmichen J., 2006. Lehrbuch des Pflanzenbaues Teil 1, Agroconcept Bonn, Germany.

Etana A. and Hakansson I., 1994. Swedish experiments on the persistence of subsoil compaction caused by vehicles with high axle load. Soil Till. Res., 29, 167-172. https://doi.org/10.1016/0167-1987(94)90053-1

Førland E.J., 1993. DNMI Climate, Infant Norms (in Norwegian). Norwegian Meteorological Institute, Oslo, Norway.

Gameda S., Raghavan G.S.V., McKyes E., and R.T., 1987. Subsoil comapction in a clay soil. II. Natural Alleviation. Soil Till. Res., 10, 123-130. https://doi.org/10.1016/0167-1987(87)90038-9

Gomez J.A., Giraldez J.V., Pastor M., and Fereres E., 1999. Effects of tillage method on soil physical properties, infiltration and yield in an olive orchard. Soil Till. Res., 52, 167-175. https://doi.org/10.1016/s0167-1987(99)00078-1

Gysi M., Ott A., and Fluhler H., 1999. Influence of single passes with high wheel load on a structured, unploughed sandy loam soil. Soil Till. Res., 52, 141-151. https://doi.org/10.1016/s0167-1987(99)00066-5

Hallett P.D., Gordon D.C., and Bengough A.G., 2003. Plant influence on rhizosphere hydraulic properties: direct measurements using a miniaturized infiltrometer. New Phytologist, 157, 597-603. https://doi.org/10.1046/j.1469-8137.2003.00690.x

Hanssen-Bauer I., Førland E.J., Haddeland I., Hisdal H., Mayer S., Nesje A., Nilsen J.E.Ø., Sandven S., Sandbø A.B., Sorteberg A., and Ådlandsvik B., 2015. Climate in Norway 2100 (in Norwegian). Norwegian Climate Service Center, NCCS rapport 2/2015.

Hartge K.H., 1993. Saturated hydraulic conductivity measurment at soil core samples and its evaluation. Soil Technol., $6,115-121$.

Hartge K.H. and Horn R., 2009. Die physikalische Untersuchung von Böden. Schweitzerbart'sche Vertragsbuchhandlung, Stuttgart, Germany.

Hartmann P., Zink A., Fleige H., and Horn R., 2012. Effect of compaction, tillage and climate change on soil water balance of arable luvisols in Northwest Germany. Soil Till. Res., 124, 211-218.

https://doi.org/10.1016/j.still.2012.06.004

Håkansson I. and Reeder R.C., 1994. Subsoil compaction by vehicles with high axle load extent, persistence and crop response. Soil Till. Res., 29, 277-304.

https://doi.org/10.1016/0167-1987(94)90065-5

Håkansson I., Voorhees W.B., Elonen P., Raghavan G.S.V., Lowery B., Vanwijk A.L.M., Rasmussen K., and Riley
H., 1987. Effect of high axle-load traffic on subsoil compaction and crop yield in humid regions with annual freezing. Soil Till. Res., 10, 259-268.

https://doi.org/10.1016/0167-1987(87)90032-8

Horn R. and Fleige H., 2003. A method for assessing the impact of load on mechanical stability and on physical properties of soils. Soil Till. Res., 73, 89-99. https://doi.org/10.1016/s0167-1987(03)00102-8

Horn R. and Fleige H., 2009. Risk assessment of subsoil compaction for arable soils in Northwest Germany at farm scale. Soil Till. Res., 102, 201-208. https://doi.org/10.1016/j.still.2008.07.015

Horn R. and Smuker A., 2005. Structure formation and its consequences for gas and water transport in unsaturated arable and forest soils. Soil Till. Res., 82, 5-14.

Horn R., Way T., and Rostek J., 2003. Effect of repeated tractor wheeling on stress/strain properties and consequences on physical properties in structured arable soils. Soil Till. Res., 73, 101-106. https://doi.org/10.1016/s0167-1987(03)00103-x

Jabro J.D., Iversen W.M., Evans R.G., Allen B.L., and Stevens W.B., 2014. Repeated freeze-thaw cycle effects on soil compaction in a clay loam in Northeastern Montana. SSSAJ 78, 737-744. https://doi.org/10.2136/sssaj2013.07.0280

Keller T., Sandin M., Colombi T., Horn R., and Or D., 2019. Historical increase in agricultural machinery weights enhanced soil stress levels and adversely affected soil functioning. Soil Till. Res., 194, 1-11. https://doi.org/10.1016/j.still.2019.104293

Kim H., Anderson S.H., Motavalli P.P., and Gantzer C.J., 2010. Compaction effects on soil macropore geometry and related parameters for an arable field. Geoderma, 160, 244251. https://doi.org/10.1016/j.geoderma.2010.09.030

Kværno S.H. and Øygarden L., 2006. The influence of freezethaw cycles and soil moisture on aggregate stability of three soils in Norway. Catena, 67, 175-182.

https://doi.org/10.1016/j.catena.2006.03.011

Lamandé M., Berisso F.E., Alakukku L., Wildenschild D., and Schønning P., 2012. Subsoil compaction of a clay soil persists three decades after heavy wheel traffic. In: Soil compaction - effects on soil functions and strategies for prevention. NJF seminar 448- Helsinki, Finland.

Lebert M., Boken H., and Glante F., 2007. Soil compaction indicators for the assessment of harmful changes to the soil in the context of the German Federal Soil Protection. Act. J. Environ. Manag., 82, 388-397.

https://doi.org/10.1016/j.jenvman.2005.11.022

Lebert M., Brunotte J., and Sommer C., 2004. Ableitung von Kriterien zur Charakterisierung einer schädlichen Bodenveränderung. entstanden durch nutzungsbedingte Verdichtung von Boeden/Regelung zur Gefahrenabwehr. 46-04/Ed. Umweltbundesamt.

Lipiec J., 2012. Crop responses to soil compaction. In: Soil compaction - effects on soil functions and strategies for prevention. NJF seminar 448. NJF, Helsinki, Finland.

Löfkvist J., 2005. Modifying soil structure using plant roots. Ph.D. Thesis, Swedish University of Agricultural Sciences, Uppsala, Sweden.

Manen J., Benestad R., and Haugen J.E., 2011. Analysis of short term precipitation in Norway 1967-2010. Norwegian Meterological Institute, Oslo, Norway. 
Mordhorst A., Fleige H., Burbaum B., Filipinsk M., and Horn R., 2019. Natural and anthropogenic compaction in North Germany (Schleswig-Holstein): Verification of harmful subsoil compactions. Soil Use Manag., 2020; 00:1-14. https://doi.org/10.1111/sum.12631

Pagliai M. and Vignozzi N., 2002. The soil pore system as an indicator of soil quality. In: Sustainable Land Management - Environmental Protection: A Soil Physical Approach, 35, 71-82.

Pagliai M., Vignozzi N., and Pellegrini S., 2004. Soil structure and the effect of management practices. Soil Till. Res., 79, 131-143. https://doi.org/10.1016/j.still.2004.07.002

Peng X. and Horn R., 2007. Anisotropic shrinkage and swelling of some organic and inorganic soils. Eur. J. Soil Sci., 58, 98-107. https://doi.org/10.1111/j.1365-2389.2006.00808.x

Peth S., 2004. Bodenphysikalische Untersuchungen zur Trittbelastung von Böden bei der Rentierweide-wirtschaft an borealen Wald und subarktisch-alpinen Tundrenstandorten. Ph.D. Thesis, Christian Albrechts Universitaet Kiel, Schriftenreihe Nr. 64, Kiel, Germany.

Peth S., Nellesen J., Fischer G., and Horn R., 2010. Noninvasive $3 \mathrm{D}$ analysis of local soil deformation under mechanical and hydraulic stresses by $\mu \mathrm{CT}$ and digital image correlation. Soil Till. Res., 111, 3-18. https://doi.org/10.1016/j.still.2010.02.007

Peth S., Rostek J., Zink A., Mordhorst A., and Horn R., 2009. Soil testing of dynamic deformation processes of arable soils. Soil Till. Res., 106, 317-328. https://doi.org/10.1016/j.still.2009.10.007

Pulido-Moncada M., Munkholm L.J., and Schjønning P., 2019. Wheel load, repeated wheeling, and traction effects on subsoil compaction. Soil Till. Res., 186, 300-309. https://doi.org/10.1016/j.still.2018.11.005

Raper R.L., 2005. Agricultural traffic impacts on soil. J. Terramech., 42, 259-280. https://doi.org/10.1016/j.jterra.2004.10.010

Rasmussen K.J., 1999. Impact of ploughless tillage on yield and soil quality: A Scandinavian review. Soil Till. Res., 53, 3-14. https://doi.org/10.1016/s0167-1987(99)00072-0

Riggert R., Seehusen T., Fleige H., Børresen T., Riley H., and Horn R., 2017. Regenerationswirkung im Unterboden eines Ackerstandortes in Südnorwegen fünf Jahre nach der Belastung. In: DBG-Jahrestagung Deutsche Bodenkundliche Gesellschaft (Ed. D.B. Gesellschaft). Goettingen, Germany.

Rogger M., Agnoletti M., Alaoui A., Bathurst J.C., Bodner G., Borga M., Chaplot V., Gallart F., Glatzel G., Hall J., Holden J., Holko L., Horn R., Kiss A., Kohnová S., Leitinger G., Lennartz B., Parajka J., Perdigão R., Peth S., Plavcová L., Quinton J.N., Robinson M., Salinas J.L., Santoro A., Szolgay J., Tron S.H., van den Acker J.J.H., Viglione A., and Böschl G., 2017. Land use change impacts on floods at the catchment scale: Challenges and opportunities for future research. Water Res. Res., 53, 5209-5219. https://doi.org/10.1002/2017wr020723
Saini G.R., 1978. Soil compaction and freezing and thawing. Soil Sci. Soc. America J., 42, 843-844. https://doi.org/10.2136/ sssaj1978.03615995004200050042x

Seehusen T., Børresen T., Rostad B.I., Fleige H., Zink A., and Riley H., 2014a. Verification of traffic-induced soil compaction after long-term ploughing and 10 years minimum tillage on clay loam soil in South-East Norway. Acta Agric. Scand., Sect. B, 64, 312-328. https://doi.org/10.1080/09064710.2014.907582

Seehusen T., Riley H., Riggert R., Fleige H., Børresen T., Horn R., and Zink A., 2014b. Traffic- induced soil compaction during manure spreading in spring in South-East Norway. Acta Agric. Scand., Sect. B, 64, 220-234. https://doi.org/10.1080/09064710.2014.902097

Seehusen T. and Uhlen A.K., 2019. Analyses of Yield Gaps for the production of wheat and barley in Norway. NIBIO Rapport; 5(166).

Sogn L. and Hauge N.H., 1976. Autumn season experiments with varieties of spring wheat, barley and oats (in Norwegian). Research Department-Norwegian Grain Corporation.

Wang L., Wang H., Tian Z., Lu Y., Gao W., and Ren T., 2020a. Structural changes of compacted soil layers in Northeats China due to Freezing-Thawing processes. Sustainability, 12, 13. https://doi.org/10.3390/su12041587

Wang X., Wang C., Wang X., and Huo Z., 2020b. Response of soil compaction to the seasonal freezing-thawing process and the key controlling factors. Catena, 184, 10. https://doi.org/10.1016/j.catena.2019.104247

Wiermann C. and Horn R., 2000. Effect of different tillage systems on the recovery of soil structure following a single compaction event. Advances Geoecol., 32, 339-350.

Wiermann C., Werner D., Horn R., Rostek J., and Werner B., 2000. Stress/strain processes in a structured unsaturated silty loam Luvisol under different tillage treatments in Germany. Soil Till. Res., 53, 117-128. https://doi.org/10.1016/s0167-1987(99)00090-2

Wolkowski R.P., 1990. Realtionship between wheel-trafficinduced soil compaction, nutrient availability, and crop growth: a review J. Prod. Agric., 3, 461-469. https://doi.org/10.2134/jpa1990.0460

Zhai X. and Horn R., 2019. Dynamics of pore functions and gas transport parameters in artificially ameliorated soils due to static and cyclic loading. Geoderma, 337, 300-310. https://doi.org/10.1016/j.geoderma.2018.09.039

Zink A., Fleige H., and Horn R., 2010. Load risks of subsoil compaction and depths of stress propagation in arable luvisols. Soil Sci. Soc. America J., 74, 1733-1742. https://doi. org/10.2136/sssaj2009.0336

Zink A., Fleige H., and Horn R., 2011. Verification of harmful subsoil compaction in loess soils. Soil Till. Res., 114, 127134. https://doi.org/10.1016/j.still.2011.04.004 